\title{
EFFECT OF DISCHARGE ENERGY AND CAVITY GEOMETRY ON FLAME IGNITION BY TRANSIENT PLASMA
}

\author{
Jianbang Liu ${ }^{1,2}$, Fei Wang ${ }^{1}$, Long C. Lee ${ }^{1}$, N. Theiss ${ }^{2}$, Paul D. Ronney ${ }^{2}$, and Martin A. Gundersen ${ }^{1, *}$ \\ Department of Electrical Engineering ${ }^{1}$ and Department of Aerospace and Mechanical Engineering ${ }^{2}$ \\ University of Southern California, Los Angeles, CA 90089
}

\begin{abstract}
Effects of number of ignition site on burning times and comparison between pulsed corona and spark discharges with single ignition site and the same energy show that there are two possible mechanisms - chemical and geometric effects, which contribute to shortening delay and rise times of pulsed corona ignitions, respectively. Burning time shortening has also be demonstrated in a geometrically IC engine like combustion chamber at elevated pressure. Discharge efficiency of pulsed corona discharge is observed much higher than spark discharge.
\end{abstract}

\section{INTRODUCTION}

Facing diminishing fossil fuel reserves and stringent government regulations, automotive industry are under strong pressure of raising thermal efficiency and reducing harmful emission. Premixed burning of very lean combustible mixtures has been one of the promising ways to solve these problems. To obtain high thermal efficiency, an ideal IC engine cycle is desirable which include a high ratio compression followed by constant-volume combustion at the minimum cylinder volume. Unfortunately, lean mixtures generally do not burn sufficiently rapidly to approach the ideal constant-volume combustion even moderately closely when conventional spark ignition sources are used. One way to approach the ideal constant-volume cycle is to adopt spatially extensive or multi-site ignition sources to increase the burning rate. . Spatially extensive ignition sources also have the potential for lowering requirements for flow turbulence intensity inside IC engines which, while necessary for IC engines to accelerate both mixing and burning rates, also causes higher heat loses to walls. Laser ignition, which is one of ignition sources producing spatially extensive ignition, has actually been demonstrated ${ }^{1}$ to provide higher thermal efficiency for a given $\mathrm{NO}_{\mathrm{x}}$ emission level per unit work Unfortunately, very low energy efficiency and necessity of optical access make laser ignition far from practical. Thus a practical means that would provide spatially extensive ignition while not requiring significant modification of IC engines is desirable for premixed lean burn IC engines. Improvements in flame ignition techniques are also of interest for certain advanced combustion engines including pulse detonation ${ }^{2-4}$, high altitude relight ${ }^{5}$ of jet turbines, natural gas ${ }^{6}$ and supersonic transport aircraft ${ }^{7}$.

Transient plasma (or pulsed corona) discharges is the transient phase of electric discharge before arc forming. It is quite different from conventional spark discharge since arc processes is completely excluded. There are two major differences between pulsed corona discharge and spark discharge. Phenomenally pulsed corona discharge produces multiple discharge channels simultaneously which distribute in a large (compared to spark discharge) space volume making spatially extensive ignition possible. Previous investigations ${ }^{8-11}$ show that producing 10 s even 100 s discharge channels simultaneously is possible. Another major difference is that pulsed corona discharge has higher electron energy (10$20 \mathrm{eV}){ }^{12}$ than spark discharge $(1 \mathrm{eV})$. The electron energy level of corona discharge is much closer to dissociation and ionization levels of many molecules, that implies possibility of higher radical production. Therefore one could 
expect pulsed corona might provide spatially extended ignition and higher burning rates, both of which are desirable for raising thermal efficiency of internal combustion engines. Similar high-voltage nanosecond discharges ${ }^{13-16}$ have been reported as a potential new method for flame ignition and hypersonic flow control.

In this paper we will report effects of discharge energy and cavity geometry on flame ignition by pulsed corona discharge.

\section{EXPERIMENT}

\section{Experiment setup}

A detailed description of experiment setup used for transient plasma discharge has been given elsewhere ${ }^{8}$. Only a brief outline will be given here (Fig. 1). Pulsed corona discharge was created by a high voltage electric pulse generator, which provides electric pulses typically of maximum $60 \mathrm{KV}$ peak voltage, 100 ns pulse width and up to 1 jour pulse energy. Two combustion chambers with different geometry are studied. The first one is a cylinder with 2.5" inner diameter (Fig. 1). Along the axis of the cylindrical chamber there is an interchangeable electrode (inner electrode) served as high voltage anode. Cylinder served as cathode and was grounded Another combustion chamber has a pancake shape and is geometrically similar to car cylinder chamber at the moment of ignition (Fig.2) with a ring shape electrode (dia: 1.5"). For comparison, spark discharge was also available in these two combustion chambers. For cylindrical combustion chamber, a plain wire electrode (1 $\mathrm{mm}$ gap) was placed at center of the cylinder. For pancake combustion chamber, a commercial available spark plug was used. In both cases, a commercially available car circuit provided electric pulse for ignition. Pressure history is measured with a pressure transducer (ASCX) with response time of $0.1 \mathrm{~ms}$ (for cylindrical combustion chamber) or with a Kistler pressure transducer (for pancake combustion chamber) with $100 \mathrm{KHz}$ response frequency. Voltage and current were measured with a voltage divider.(1000:1) and a current transformer (0.1V/A). Pressure, voltage and current signals were recorded with a digital oscilloscope (Tektronix 640C). Electric pulse energy was calculated from product of voltage and current then integrated respect to time.

In cylindrical combustion chamber, experiments were conducted for four kinds of electrodes (Fig.3): single pin, 1 ring with multi pin, multi ring with 2 pins each ring and rod electrodes. Different electrode structures were intended to produce different numbers of ignition site. In single pin electrode case, the corona discharge concentrates in a narrow space volume, in spite of the corona discharge is still multi-channeled as shown in an image on reference paper ${ }^{10}$. Therefore, single pin electrode experiments show single ignition site effects. 1 ring with multi-pin electrode and multi-ring with 2 pins each ring electrodes were intended to show multi-ignition site effects. Rod electrode is expected creating many (10s to $100 \mathrm{~s}$ ) discharge channels simultaneously ${ }^{8-11}$ and shows large number ignition sites number effects.

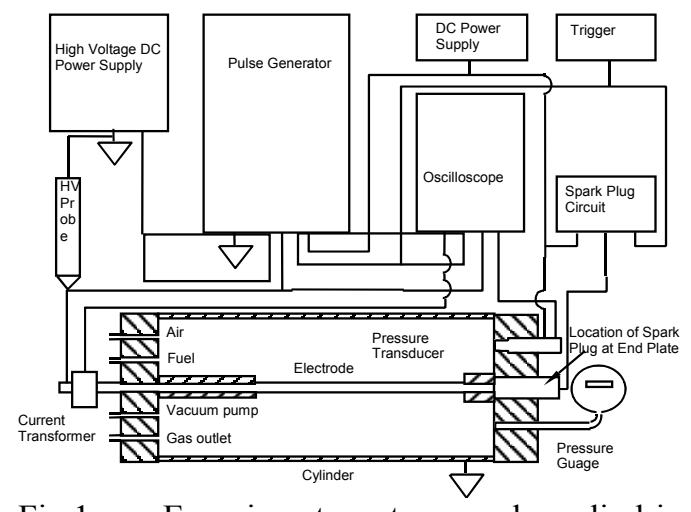

Fig.1 Experiment setup and cylindrical combustion chamber.

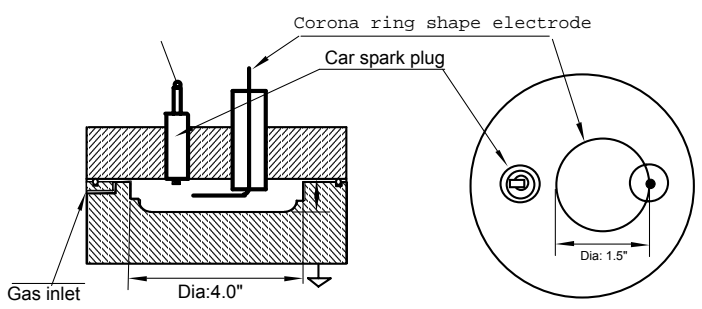

Fig.2 Car cylinder-like combustion chamber

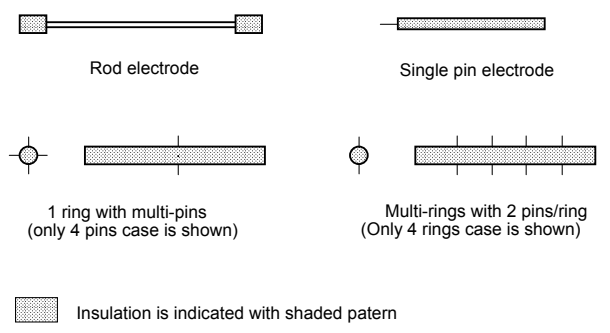

Fig.3 Various inner electrode for cylindrical combustion cahmber. 
$\underline{\text { Experimental results }}$

\section{(i) Minimum ignition energy}

Minimum ignition energy is defined as the lowest energy necessary for ignited flame. Fig. 4 shows a boundary between successful and unsuccessful ignitions of $\mathrm{CH}_{4} /$ Air mixture corresponding to $50 \%$ ignition possibility for single pin electrode corona discharge ignition. Also shown in Fig. 4 is minimum ignition energy for spark ignition (Lewis and von Elbe ${ }^{17}$ ) Minimum ignition energy of single pin electrode pulsed corona discharge ignition is considerably higher than spark discharge ignition. In stoicheometric case, they are 60 and $0.4 \mathrm{~mJ}$, respectively. Both type of ignition have their lowest minimum ignition energy not at stoicheometric condition but at slightly leaner composition. That implies they might have similar Lewis number effect.

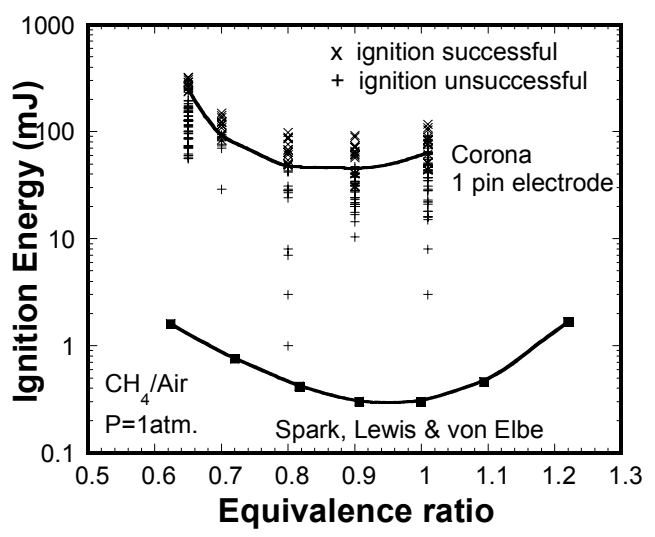

Fig.4. Ignition energy versus equivalence ratio for corona discharge with single pin electrode and spark discharge (Lewis and von Elbe ${ }^{17}$ data)

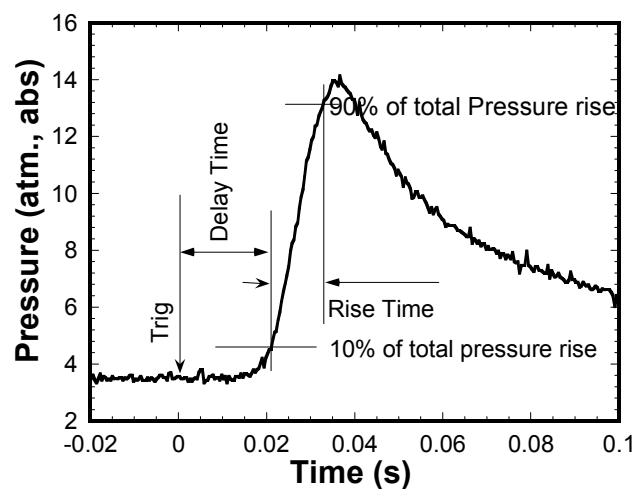

Fig. 5 Typical pressure history and definitions of rise and delay time.

\section{(ii) Burning times}

A typical pressure history of combustion in a constant volume chamber is shown in Fig. 5. After trig, pressure does not rise immediately but delay for a period of time. The time lapse between trig and pressure rises to $10 \%$ of its total pressure rise is defined as delay time. The time lapse between $10 \%$ and $90 \%$ of its total pressure rise is defined as rise time. By burning times we mean both delay and rise times.

To observe number of ignition site effect on burning times, various electrodes were used to produce different numbers of ignition site. Fig. 6 shows results of single pin electrode. In this single ignition site case, rise time was almost independent of energy and delay time decreased gradually as energy increasing. Then we changed the number of ignition site by varying electrode. Fig.7 shows the burning time of 4 rings with 2 pin/ring $(4 \times 2)$ electrode. Comparing single pin with $4 \times 2$ electrode, the delay time did not change very much. But the rise time of $4 \times 2$ electrode showed a rapid decreasing as energy increasing. That means number of ignition site has a significant effect on rise time but not on delay time. To further verify this result, burning time of rod electrode, which could produce 10 s even 100 s discharge channels simultaneously ${ }^{8}$, was measured (Fig. 8). The results were very close to the results of $4 \times 2$ electrode.

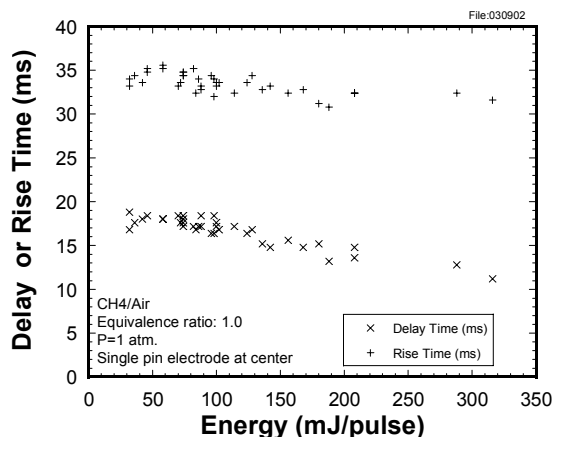

Fig. 6 Delay and rise time versus energy. Pulsed corona discharge ignition, Single pin electrode, $\mathrm{CH}_{4} /$ Air, Equivalence ratio: 1.0 


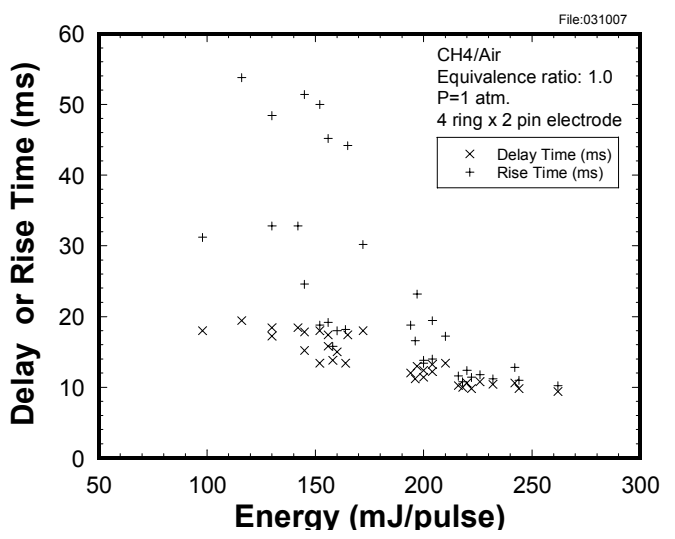

Fig. 7 Delay and rise time versus energy. Pulsed corona discharge ignition, 4 ring with 2 pins/ring electrode, $\mathrm{CH}_{4} / \mathrm{Air}$, Equivalence ratio: 1.0

Fig. 9 summaries rise time data for different electrode configurations. Since shorter rise time, lower energy and reliable ignition are desirable, the $4 \times 2$ electrode might be the best choice after tradeoff between these parameters.

(iii) Comparison between single pin electrode pulsed corona and spark discharges

To make a comparison between pulsed corona and spark discharge ignition, burning times were measured for ignitions by pulsed corona with 1 pin electrode and spark discharges. Both types of discharges have only one ignition site, therefore number of ignition site effects were excluded. In addition, the energy was kept the same. Results (Fig. 10) show that pulsed corona ignition has a significant low delay time than spark ignition even in case of the same number of ignition site and energy. Rise time had also been measured (Fig.11) and shows that there is no big difference between pulsed corona with 1 pin electrode and spark discharge ignitions. That implies if number of ignition site and energy are the same, rise times of pulsed corona and spark discharges will be about the same. Fig. 11 also includes the rise time of pulsed corona discharge ignition with $4 \times 2$ electrode, which has much lower rise time than both 1 pin electrode pulsed corona and spark

discharges. That implies rise time can be significantly reduced by adopting multi-site ignition.

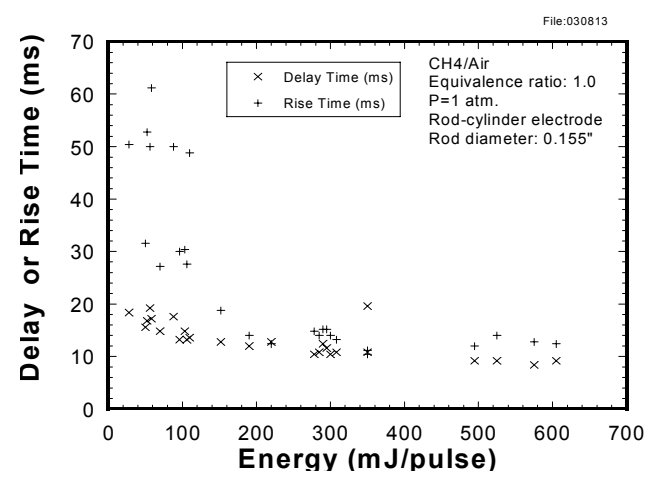

Fig. 8 Delay and rise time versus energy. Pulsed corona discharge ignition, rod electrode, $\mathrm{CH}_{4}$ /Air, Equivalence ratio: 1.0

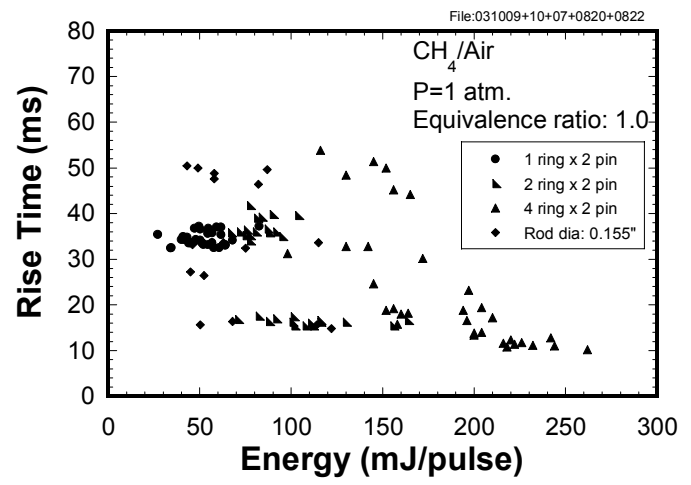

Fig 9. Summery of rise times of different electrodes

(iv) Experiments in a IC engine like combustion chamber

An geometrically IC engine like combustion chamber has been built as shown in Fig. 2. Pulsed corona discharge has successfully ignited $\mathrm{CH} 4 /$ Air mixture in this chamber with equivalence ratio $\Phi=1.0$ and pressure of $10 \mathrm{~atm}$.. Pressure histories have also been measured for both pulsed corona and spark discharges (Fig.12). Pulsed corona discharge ignition shows a shorter rise time $(10 \mathrm{~ms})$ than spark discharge (19 ms) by a factor of 2 even though the energy of former $(14 \mathrm{~mJ})$ is lower than later $(39 \mathrm{~mJ})$. Delay time of corona discharge ignition $(20 \mathrm{~ms})$ was longer than spark discharge ignition $(13 \mathrm{~ms})$, but it might be compensated by advance ignition timing in IC engines. 


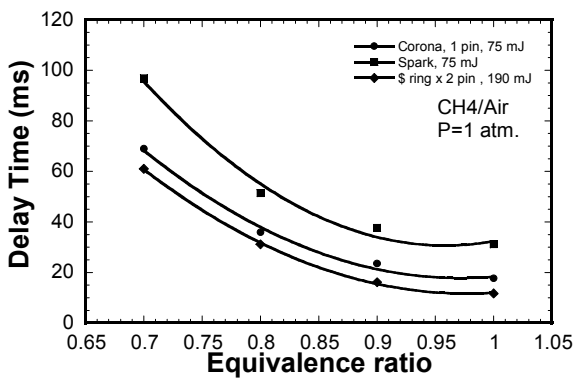

Fig. 10 Delay time versus equivalence ratio for pulsed corona with $1,4 \times 2$ pin electrode and spark diacharges

\section{(v) Discharge efficiency}

Discharge efficiency is defined as the ratio between energy absorbed by gas and total electric energy released by discharge:

$$
\text { Disch arg e efficiency } \equiv \frac{E_{\text {absorbed by gas }}}{\int V I d t}
$$

where $V$ and $I$ are discharge voltage and current, respectively; $t$ time. $E$ absorbed by gas can be measured by measuring pressure rise caused by discharge only in a constant volume chamber and evaluated by

$$
E_{\text {absorbed by gas }}=\frac{V_{\text {chamber }} \Delta P}{\gamma-1}
$$

where $V_{\text {chamber }}$ is chamber volume, $\Delta P$ the pressure raised by discharge and $\gamma$ gas specific heat ratio. Fig. 13 shows experiment results for 3 different kinds of pulsed corona discharges and 2 different kinds of spark discharges. The discharge efficiencies for all kinds of pulsed corona discharge are about the same $(\sim 60 \%)$ and the same for spark discharge but with much lower discharge efficiency $(\sim 5 \%)$. It is remarkable that the discharge efficiency of pulsed corona discharge is one order of magnitude higher than that of spark discharge.

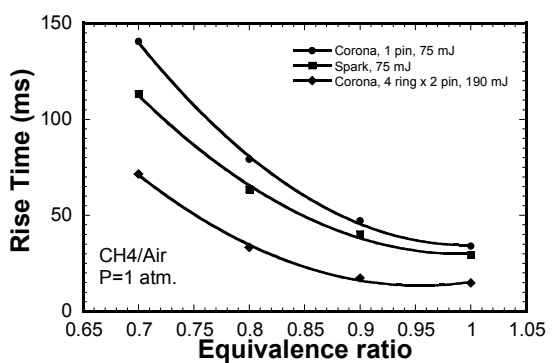

Fig. 11 Rise time versus equivalence ratio for pulsed corona with $1,4 \times 2$ pin electrode and spark diacharges

\section{DISCUSSION}

Pulsed corona discharge can provide shorter ignition delay and rise times than spark discharge. There are two possible mechanisms which might contribute to shortening burning times. As shown in Fig. 10, in case with the same number of ignition site and energy, pulsed corona discharge provides shorter delay time than spark discharge. This fact might be understood in following way. Compared with spark discharge, the much higher electron energy of pulsed corona discharge might produce more radicals and, in term, shorten delay time. This is a chemical mechanism. Another mechanism is multi-site ignition. As shown Figs 6-8, number of ignition site has significant effect on shortening rise time. This is a geometric effect. Properly chose discharge conditions (geometries of electrode and combustion chamber, voltage, ...) may shorten both delay and rise time by a factor of 3 as previous reported ${ }^{8-11}$.

Pulsed corona discharge has a higher minimum ignition energy than spark discharge. This factor might be due to its large discharge volume compared to spark discharge. Pulsed corona discharge is inherently a multi-channel discharge even in single pin electrode case. Its energy distributes in many discharge channels. When measuring minimum ignition energy, 
energy is always intended to be as low as possible. It might be expected that only a few discharge channels (perhaps only one) have high enough energy density to ignite flame. From ignition point of view, all the energy distributes in the rest discharge channels are wasted. Although it might still contribute to enhance flame propagation after ignition. The property of multi-ignition site of pulsed corona discharge makes rise time shortening possible. But it also causes high minimum ignition energy.

Results in IC engine like combustion chamber and discharge efficiency measurement are encouraging. It might be of interest by some combustion engine applications.

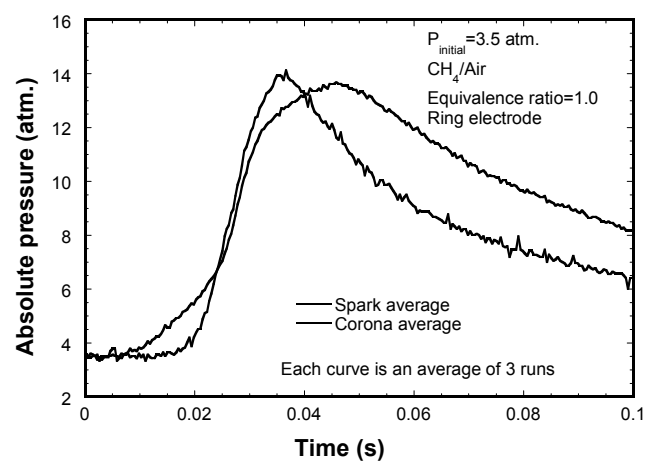

Fig. 12 Pressure histories in a IC engine like combustion chamber.

\section{References}

[1]. J. D. Dale, P. R. Smy, and R. M. Clements, "Laser Ignited Internal Combustion Engine - An Experimental Study," SAE Paper No. 780329 (1978.)

2] Kailasanath, K., "Review of propulsion applications of detonation waves," AIAA J., Vol. 38, pp. 1698-1708 (2000); Kailasanath, K., "A review of PDE research - performance estimates," AIAA Paper 2001-0474 (2001).

[3] Schauer, F., Stutrud, J., Bradley, R., "Detonation initiation studies and performance

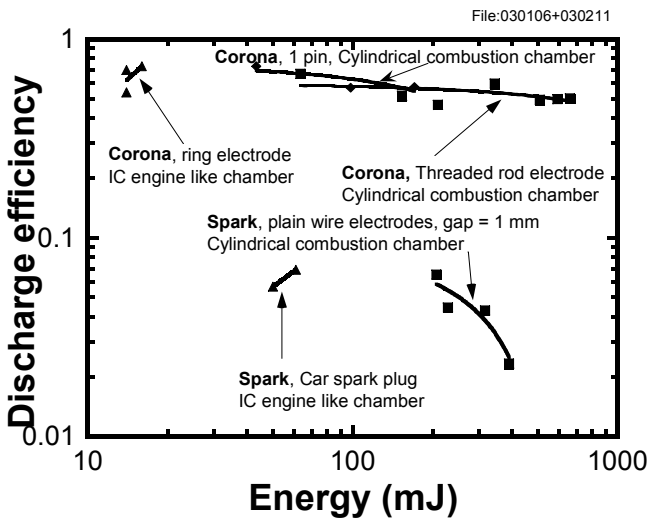

Fig. 13 Discharge efficiency versus energy for 3 different kinds of pulsed corona discharges and 2 different kinds of spark discharges.

The authors would like to express their sincere thanks to ONR (Grant N00014-00-10098), AFOSR (Grant F49620-01-1-0322), ARO (Grant DAAD19-01-1-0698) and DOE (Grant DE-FC26-02NT41336) for their support.

\footnotetext{
* Author to whom correspondence should be directed: Martin A. Gundersen, Department of Electrical Engineering-Electrophysics, University of Southern California, Los Angeles, CA 90089-0271 mag@usc.edu
}

results from pulsed detonation engine applications," AIAA Paper No. 2001-1129 (2001).

[4] Bussing, T. R. A., Bratkovich, T. E., and Hinkey, J. B., "Practical Implementation of Pulse Detonation Engines," AIAA Paper 97-2748, July 1997.

5] Cote, T., Ridley, J.D. Clements, R.M. Smy, P.R., "The ignition characteristics of igniters at 
sub-atmospheric pressure", Combust. Sci. and Tech. Vol.48, pp 151-162, 1986.

[6] D. Yossefi, S.J. Maskell, S.J. Ashcroft and M.R. Belmont,'Ignition source characteristics for naturel-gas-buring vehicle engines", Proc Instn. Mech Engrs Vol 214 Part D 171-180,2000

[7] M. Lavid, A.T. poulos, S.K. Gulati, Y. Nachshon and J.G. Stevens, "Excimer laser relight for the supersonic commercial transport aircraft” SPIE Vol. 1862 , 59-70 (1993)

8] Jian-Bang Liu, Paul D. Ronney and Martin A. Gundersen, "Premixed flame ignition by transient plasma discharges", Proceedings of the Third Joint Meeting of the U.S. Sections, The Combustion Institute, Paper B-25, 2003 March 16-19, Chicago, Illinois

[9] JianBang Liu, Paul D. Ronney, Fei Wang, L.C. Lee and Martin Gundersen, "Transient plasma ignition for lean burn application”, 41st Aerospace Sciences Meeting, AIAA paper No. 2003-6208 (2003), Reno, Nevada, 6 - 9 Jan 2003

[10] J.B.Liu, P.D.Ronney and M.A.Gundersen, "Premixed Flame Ignition by Transient Plasma Discharges", 29 ${ }^{\text {th }}$ Symposium (International) on Combustion, Combustion Institute, July 21 26, 2002, Sapporo, Japan.

[11] J.B.Liu, P. D. Ronney and M. A. Gundersen, "Premixed flame ignition by pulsed corona discharges", Spring 2001 meeting, Western States Section, the Combustion Institute, San Diego, La Jolla, CA.
[12] E Marode,A. Goldman and M. Goldman,'High pressure discharge as a trigger for pollution control" in Non-thermal plasma techniques for pollution control, Ed. by B.M. Penetrante and S.E. Schultheis, Springer-Verlag Berlin Heidelberg 1993 167-190

[13] R. Maly, "Spark Ignition: Its physics and Effect on the Internal Combustion Engine", In "Fuel Economy: Road Vehicles Powered by Spark Ignition Engines" ed. by Hilliard, J.C. and Springer, G.S., Plenum Press, NY,1983, 91-148

[14] R. Maly, and M. Vogel, "Initiation and propagation of flame front in lean $\mathrm{CH}_{4}$-Air mixtures by the three models of the ignition spark", Proceedings of the $17^{\text {th }}$ Symposium (International) on Combustion, the Combustion Institute, Vol. 17, 821-831 1978

[15] N.B. Anikin, E.I. Mintoussov, S.V. Pancheshnyi, D.V. Roupassov, V.E. Sych, and A.Yu Starikovskii, "Nonequilibrium plasma and its applications for combustion and hypersonic flow control", ", 41st Aerospace Sciences Meeting, Reno, Nevada, 6 - 9 Jan 2003

[16] S.M. Bozhenkov, S.M. Starikovskaia, V.A.Sechenov, A.Yu Starikovskii, and V.P. Zhukov, "Combustion mixtures ignition in a wide pressure range. Nanosecond high-voltage discharge ignition", ", 41st Aerospace Sciences Meeting, Reno, Nevada, 6 - 9 Jan 2003

[17] B. Lewis and G. von Elbe, "Combustion, Flame and Explosions of Gases" $3^{\text {rd }}$ Ed. Academic, Orlando,1987, p.357. 